ARTICLE

https://doi.org/10.1038/s41467-021-27588-8

\title{
Nanoparticles and photochemistry for native-like transmembrane protein footprinting
}

\author{
Jie Sun (10) ${ }^{1}$, Xiaoran Roger Liu (1) ${ }^{1}$, Shuang $\mathrm{Li}^{2}$, Peng He $\mathrm{H}^{2}$, Weikai $\mathrm{Li}^{2 \bowtie}$ \& Michael L. Gross (1) ${ }^{1 凶}$
}

Mass spectrometry-based footprinting can probe higher order structure of soluble proteins in their native states and serve as a complement to high-resolution approaches. Traditional footprinting approaches, however, are hampered for integral membrane proteins because their transmembrane regions are not accessible to solvent, and they contain hydrophobic residues that are generally unreactive with most chemical reagents. To address this limitation, we bond photocatalytic titanium dioxide $\left(\mathrm{TiO}_{2}\right)$ nanoparticles to a lipid bilayer. Upon laser irradiation, the nanoparticles produce local concentrations of radicals that penetrate the lipid layer, which is made permeable by a simultaneous laser-initiated Paternò-Büchi reaction. This approach achieves footprinting for integral membrane proteins in liposomes, helps locate both ligand-binding residues in a transporter and ligand-induced conformational changes, and reveals structural aspects of proteins at the flexible unbound state. Overall, this approach proves effective in intramembrane footprinting and forges a connection between material science and biology.

\footnotetext{
${ }^{1}$ Department of Chemistry, Washington University in St. Louis, One Brookings Drive, Box 1134 Saint Louis, MO 63130, USA. ${ }^{2}$ Department of Biochemistry

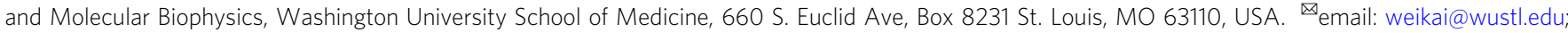
mgross@wustl.edu
} 
ntegral membrane proteins (IMPs) perform key roles in cellular signaling, transport, ahesion, and catalysis, motivating their choice for $60 \%$ of drug targets ${ }^{1}$. Although the human genome encodes $\sim 5500$ IMPs, only 200 unique structures have been determined to date by X-ray crystallography ${ }^{2}$ and cryo-EM ${ }^{3}$ owing to technical challenges and time demands. Furthermore, these approaches do not inform on protein dynamics and may suffer if the protein denatures once isolated from the native membranes. Thus, a significant need exists for methodology to investigate native protein structure in the membrane environment. Mass spectrometry (MS) may provide a solution ${ }^{4}$.

Currently, there are two major MS-based approaches to study IMPs. One is native spray conducted in the gas phase applied so far to mainly bacterial IMPs, providing ligand identification, binding stoichiometry, but no spatial information ${ }^{5,6}$. Another is chemical footprinting that, via proteomic analysis of a covalently labeled protein, offers sufficient spatial resolution to answer structural biology questions ${ }^{7-14}$. Tailored reagents can be designed to react with solvent-accessible amino acid residues to report on binding sites, conformational changes, and dynamics ${ }^{15}$. The most common footprinting approach for IMPs utilizes hydroxyl radicals $(\bullet \mathrm{OH})$ because they offer comprehensive coverage especially of hydrophobic residues. When applied on the fast photochemical oxidation of proteins (FPOP) platform, the $\cdot \mathrm{OH}$ can react in $\mu$ s to capture the protein native states and dynamics ${ }^{16,17}$.

Although several investigators have applied chemical footprinting approaches to IMPs $9,10,13$, most footprints are of solventaccessible extramembrane regions, whereas the hydrophobic transmembrane (TM) regions remain largely untouched. Footprints of the TM region of a bacterial IMP in micelles were obtained by using amphiphilic carbenes over minutes of laser and chemical precursor exposure ${ }^{8}$. In a specialized example, trapped functional water molecules were ionized by X-rays to generate - $\mathrm{OH}$ that footprints nearby regions, allowing the water molecules to be located 18,19 . Unfortunately, these methods are not yet generally applicable to IMPs, especially human IMPs that are often less stable in a detergent solution ${ }^{20-22}$.

Two significant challenges must be faced to elevate footprinting for IMPs: (i) generating broad coverage over hydrophobic TM regions to afford sufficient resolution for answering structural questions; and (ii) footprinting IMPs in their near-native state. To meet these two challenges, we developed and report here a strategy (Fig. 1a) that utilizes photocatalytic membraneassociated titanium dioxide nanoparticles $\left(\mathrm{TiO}_{2} \mathrm{NPs}\right)$ to produce, upon laser irradiation, high local concentrations of free radicals. The irradiation simultaneously initiates a Paternò-Büchi $\mathrm{PB}$ ) reaction with the phospholipids comprising the liposome, to perturb the lipid region and allow the radicals to penetrate rapidly the lipid bilayer and footprint the IMP. This strategy, named NanoPOMP (NP-promoted photochemical oxidation of membrane proteins), yields high coverage in the TM region of bacterial vitamin $\mathrm{K}$ epoxide reductase (VKOR) and enables footprinting the conformational changes of human glucose transporter 1 (hGLUT1).

\section{Results}

Design and features of NanoPOMP. The design of NanoPOMP is shown in Fig. 1a. NanoPOMP has three features. First, $\mathrm{TiO}_{2}$ $\mathrm{NPs}^{23-25}$ generate reactive oxygen radicals (e.g., $\bullet \mathrm{OH}, \mathrm{O}_{2}{ }^{-}$) to be used in a unique way for IMP footprinting. The UV laser provides sufficient energy to excite electrons to the conduction band, leaving holes $\left(\mathrm{h}^{+}\right)$on the valence band. Reactions of $\mathrm{h}^{+}$with surface-bound $\mathrm{H}_{2} \mathrm{O}$ generate $\bullet \mathrm{OH}$. Electrons in the conduction band reduce $\mathrm{O}_{2}$ to superoxide. The $\mathrm{h}^{+}$can also accept electrons directly from molecules adsorbed onto the $\mathrm{TiO}_{2}$ surface 26,27 .
Second, it is well-known that some metal oxides, such as $\mathrm{TiO}_{2}$, can reversibly bind with phosphate groups with high specificity via coordination chemistry ${ }^{28}$. Owing to the specific and reversible interactions with the phospholipids and other interactions including van der Waal forces, the $\mathrm{TiO}_{2}$ NPs attach to the surface of the liposome, which provides a near-native membrane environment for the IMP. The attached NPs generate local concentrations of $\cdot \mathrm{OH}$ during laser irradiation. Considering practicality, we can remove the insoluble NPs after footprinting.

Third, a laser-initiated $\mathrm{PB}$ reaction increases the permeability of the lipid bilayer by a $[2+2]$ cycloaddition of a double bond of the lipid with certain amount of added acetone, resulting in a fast and specific modification of the lipids ${ }^{29,30}$. The laser shot of the NanoPOMP platform has sufficient energy to accelerate the PB reaction. Although there are options, acetone was our first choice as the $\mathrm{PB}$ reagent because it is miscible with $\mathrm{H}_{2} \mathrm{O}$ and lipids, and is activated at $248 \mathrm{~nm}$ with the FPOP laser. There are three possible mechanisms that increase the permeability of the lipid bilayer: (i) acetone increases membrane fluidity and permeability, (ii) oxygen addition forms a four-membered ring structure (oxetane) by reacting with a double bond of the unsaturated lipid tail, presumably affecting the regularity and hydrophobicity of the tail, generating kinks in the bilayer, and producing defects in the membrane, and (iii) the polar oxetane group causes the modified lipids to flip toward the aqueous phase. Irrespective of mechanism, the lipid bilayer becomes more hydrophilic and permeable for hydrophilic hydroxyl radicals to access and label the transmembrane domain.

The two photochemical processes, $\bullet \mathrm{OH}$ radical production and $\mathrm{PB}$ reaction, occur rapidly and nearly simultaneously in NanoPOMP. The free radicals are generated in the vicinity of the liposome, and the membrane permeability is increased, allowing those free radicals to access the transmembrane region.

Characterization of the NanoPOMP system. Firstly, we showed that the $\mathrm{PB}$ reaction occurs under our fast footprinting condition of the NanoPOMP platform (i.e., one laser shot at a power of $23 \mathrm{~mJ})$. Using a typical NanoPOMP protocol, we flowed a mixture of POPE and acetone $/ \mathrm{H}_{2} \mathrm{O}$ and submitted the mixture to nanoPOMP, followed by characterization of the products by ESI MS. Although the POPE concentration was $32 \mu \mathrm{M}$ (to avoid contaminating the mass spectrometer), a concentration that is much lower than that of POPE when forming liposomes for NanoPOMP $(\sim 28 \mathrm{mM})$, we reasoned that if the PB reaction occurs at this concentration, it should also take place under the higher concentrations used in the NanoPOMP. The product peaks corresponding to acetone addition are clearly seen (Fig. 1c), showing that the $\mathrm{PB}$ reaction occurs upon activation by a few ns laser pulse. These conditions are appropriate for the $\mathrm{PB}$ reaction to modify the unsaturated lipid tail and to make the membrane more permeable.

Another important question is whether the attachment of $\mathrm{TiO}_{2}$ NPs perturbs the liposome, causing it to deform or even fall apart. We used electron microscopy at cryogenic temperature (CryoEM) to visualize the liposome before and after adsorption of $\mathrm{TiO}_{2}$ NPs (Fig. 1d-g) onto the surface because Cryo-EM can better maintain liposome structure compared with other methods. A control (Fig. 1d) shows the intact liposome. After incubation with NPs (1 h, room temperature (RT)), the sample was frozen immediately and imaged instantly (Fig. $1 \mathrm{e}-\mathrm{g}$ ). We clearly see that $\mathrm{TiO}_{2}$ NPs are attached securely to the surface and that the liposomes remain circular and intact. Figure $1 \mathrm{e}-\mathrm{g}$ (f and $\mathrm{g}$ with higher magnification) show, at least at this resolution, that the liposome edge is intact, suggesting that addition of $\mathrm{TiO}_{2} \mathrm{NPs}$ does not perturb the liposome structure. 


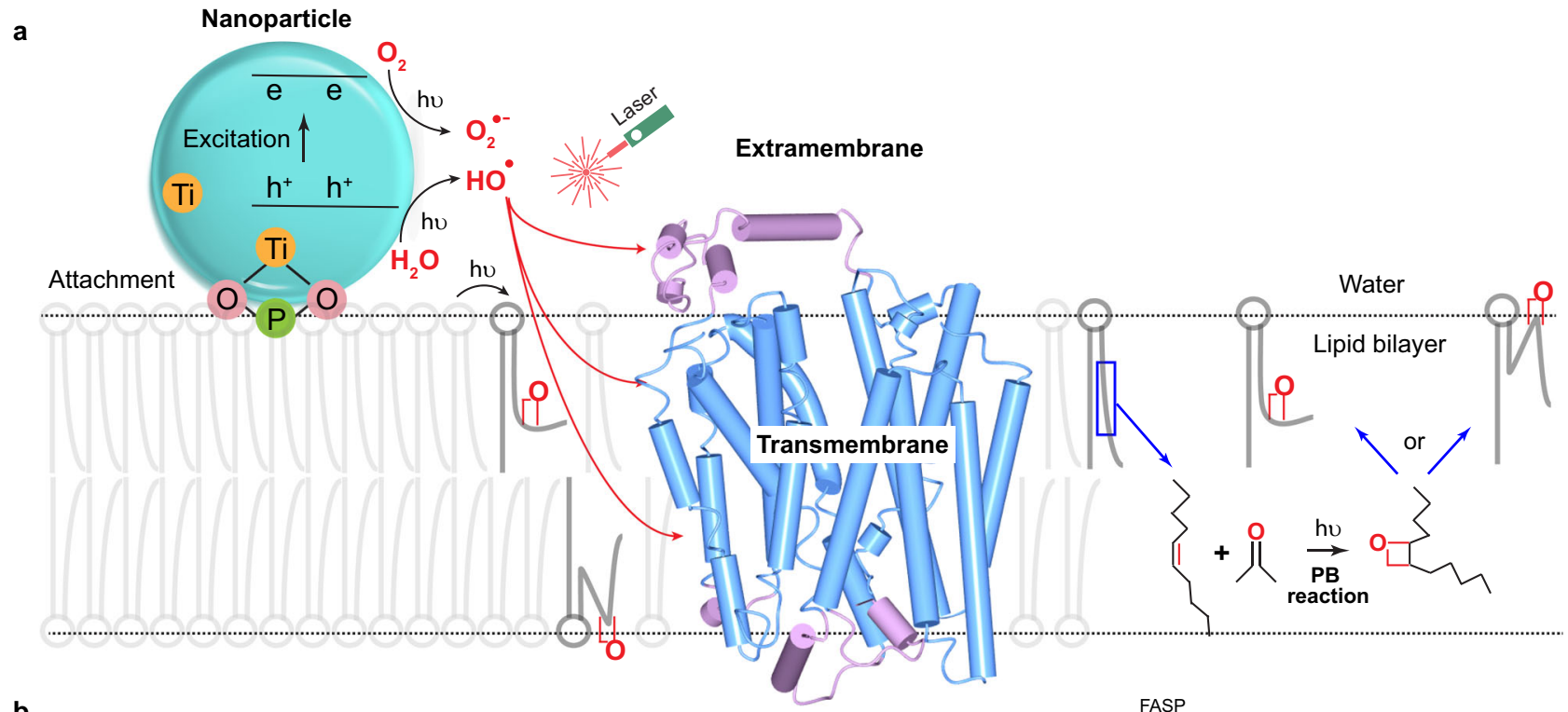

b

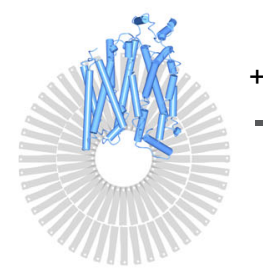

Liposomal reconsitution
of membrane protein

c

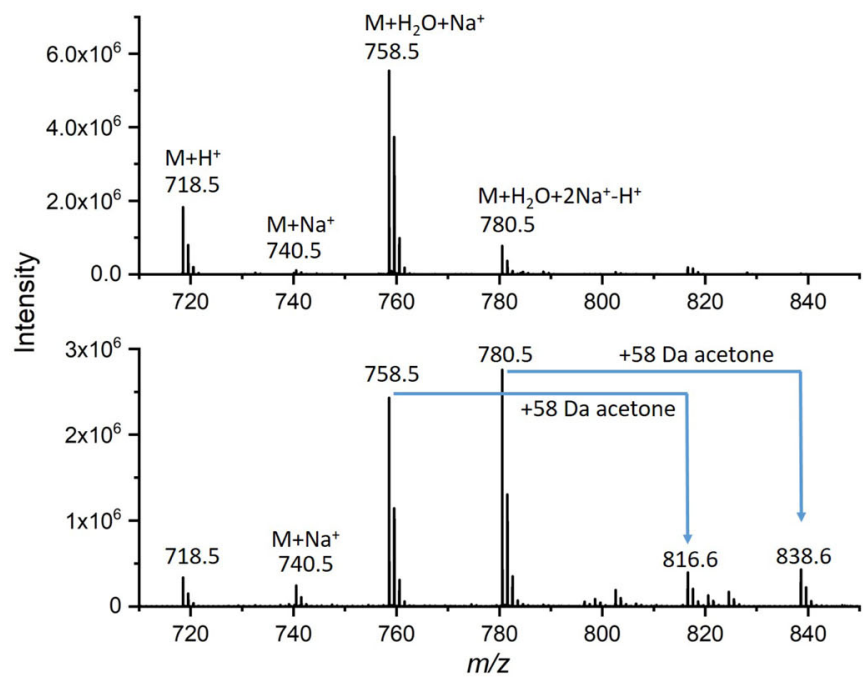

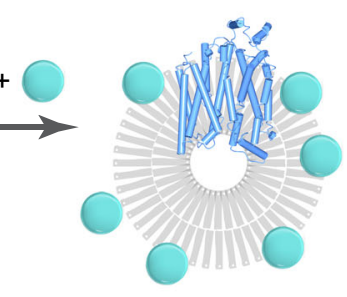

Nanoparticle attachment

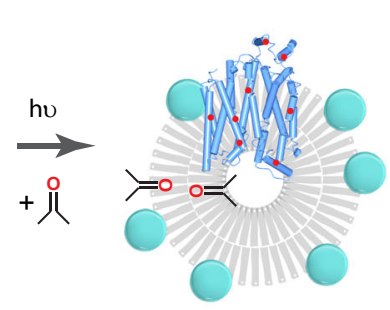

Photoactivated radical footprinting \& PB reaction

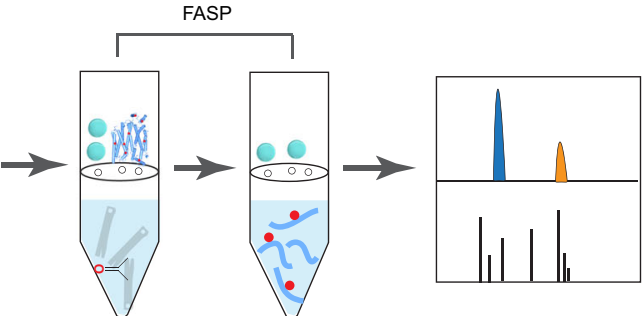

Lipid removal protein digestion
nHPLC-MS/MS
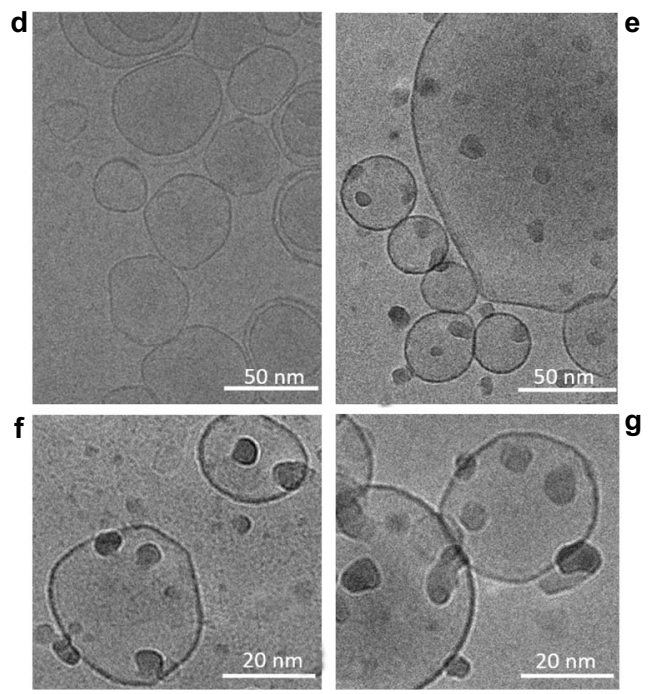

Fig. 1 Workflow and characterization of NanoPOMP. a Scheme of NanoPOMP for IMP stabilized in liposome. $\mathrm{TiO}_{2} \mathrm{NPS}$ are attached to the phosphate groups on the lipid bilayer. The liposome containing the IMP is irradiated with a $248 \mathrm{~nm} \mathrm{KrF}$ laser, generating radicals (red dots). The PB reaction of acetone and lipid double bonds generates kinks in bilayer by a reaction mechanism shown on the right. $\mathbf{b}$ Typical workflow for the NanoPOMP experiment. (Although the protein is positioned in both orientations with equal probability in a liposome, we show only one orientation as an example.) c Upper: zoomed ESI mass spectrum of POPE and acetone $/ \mathrm{H}_{2} \mathrm{O}$; lower: ESI mass spectrum of POPE and acetone $/ \mathrm{H}_{2} \mathrm{O}$ induced by NanoPOMP laser. Source data are

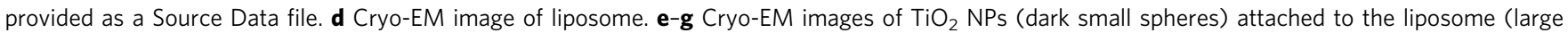
spheres), demonstrating liposome stability upon adsorption of NPs onto the surface. Higher magnification is shown in (f, $\mathbf{g}$ ) for different sections of a cryoEM grid. Experiments of $\mathbf{d}-\mathbf{g}$ are repeated twice independently with similiar results.

In addition to the imaging of the $\mathrm{TiO}_{2}$ NPs-POPE/POPG liposome system, previous studies further support the view that the NPs used here do not significantly affect the liposome structure. The liposome/NP interaction includes van der Waals, double layer, hydration, hydrophobic, thermal undulation, and protrusion forces ${ }^{31}$. The size of the NPs play a role in the interaction ${ }^{32-34}$, for example, $5 \mathrm{~nm}$ AuNPs (the particle diameter used here) have the smallest influence on the membrane compared to larger sizes ${ }^{32}$. In another case, suspensions of $\mathrm{SiO}_{2}$ NPs and DPPC liposomes are stable for months for mixtures of 
$50 \mathrm{~nm}$ liposomes interacting with nominal $4-6 \mathrm{~nm} \mathrm{SiO}_{2} \mathrm{NPs}^{35}$. Charge is another parameter that influences the interaction. Studies showed that the attachment of charged NPs improves liposome stability by increasing the absolute zeta potential of the dispersion and by introducing charges on the liposome surface ${ }^{35-37}$. Furthermore, the coordination chemistry between $\mathrm{TiO}_{2}$ and the phosphate group allows $\mathrm{TiO}_{2}$ to bind reversibly with liposomes with high specificity ${ }^{28}$, imparting stabilizing properties not found for other NPs. For example, the interaction of $\mathrm{TiO}_{2} \mathrm{NP}$ with DOPC/DOCPe/DOPS liposomes via coordination is found to be more important than charge ${ }^{38}$. Other research showed that $\mathrm{TiO}_{2}$ NPs stabilize a DPPC liposome even under the lengthy conditions needed to reach adsorption equilibrium of $\mathrm{TiO}_{2}$ with the vesicles ${ }^{39}$.

Performance optimization of NanoPOMP on bacterial VKOR, a model IMP. The second question we asked is whether the combination of a $\mathrm{PB}$ reaction initiated simultaneously by the laser pulse that generate radicals affords membrane protein footprinting. We used bacterial VKOR (PDB ID: 3KP9) to answer this question. VKOR is an integral membrane enzyme that couples vitamin $\mathrm{K}$ reduction with disulfide-bond formation, to sustain oxidative protein folding in prokaryotes and support blood coagulation in humans ${ }^{40}$. We optimized a workflow (Fig. 1b) following the footprinting (Supplementary Fig. 1) to separate the $\mathrm{TiO}_{2}$ and to remove lipids, salts, and any residual $\mathrm{TiO}_{2}$ by filteraided sample preparation (FASP ${ }^{41}$, Supplementary Fig. 2). The steps are intended to minimize contamination of the nHPLC column and the mass spectrometer with lipids. With this workflow, we could isolate the VKOR and analyze it with high $(\sim 100 \%)$ sequence coverage (Supplementary Fig. 3). The $\mathrm{TiO}_{2}$ we used here has high UV absorption (Supplementary Fig. 4) to afford sufficient quantum yield and thus catalytic reactivity to produce abundant radicals.

Next, we optimized the amount of $\mathrm{PB}$ reactant (acetone) by testing several levels from 0 to $15 \%(\mathrm{v} / \mathrm{v})$ (Fig. 2a). The number of footprinted extramembrane domain peptides remained nearly constant, whereas greater amounts of acetone presumably increase the lipid-membrane perturbation; the acetone amount that affords the highest yield of TM-domain footprints is $6 \%$ in the aqueous phase. The peptide-level results with $\mathrm{PB}$ and without $\mathrm{PB}$ clearly demonstrate that the TM regions undergo footprinting following membrane perturbation (Fig. 2f). The residue-level results (Fig. 2d, e) demonstrate, upon bilayer perturbation, that footprints are produced over almost the entire VKOR held within the liposome. Residues Y, W, F, M, T, D, and L become modified to different extents (examples of EIC and product-ion $\left(\mathrm{MS}^{2}\right.$ ) spectra are in Supplementary Figs. 5-14).

Effect of PB Reagent and $\mathrm{TiO}_{2}$ NPS on IMP's structure and activity. A potential issue to be faced is the effect of the added acetone on the protein structure. We obtained a circular dichroism spectrum of VKOR with $6 \%$ acetone and found no significant difference (Supplementary Fig. 15), indicating that secondary structure is minimally disrupted if at all. To provide further evidence that acetone is not detrimental to the tertiary structure and enzyme function, we used VKOR enzymatic activity assays (Fig. 2b). With $1 \%$ acetone, VKOR activity increased slightly probably because the substrate (vitamin $\mathrm{K}$ ) dissolved better. With $6 \%$ acetone, VKOR showed essentially no change in its enzymatic activity compared with no acetone. We conclude the amount of acetone used in this NanoPOMP protocol is in the "safe zone" to maintain VKOR structure and enzymatic activity. We also tested the enzyme activity of VKOR (Fig. 2c, Supplementary Fig. 16) in liposome (i) and VKOR in liposome incubated with $\mathrm{TiO}_{2} \mathrm{NPs}$ (ii). The results show that binding $\mathrm{TiO}_{2}$ NPs does not significantly affect the enzymatic activity, suggesting the IMP is stabilized in the liposome.

NanoPOMP mapping of a human IMP. Then, we applied NanoPOMP to another IMP, hGLUT1, which is ubiquitous in erythrocytes and blood-tissue barriers in humans and is upregulated in cancer cells. Following the workflow established for VKOR, we achieved $\sim 100 \%$ sequence coverage of hGLUT1 (Supplementary Fig. 17). In separate experiments, $\mathrm{TiO}_{2}$-FPOP mainly footprints the extra-membrane regions (Supplementary Table 3 summarizes the results of MS analysis showing EICs, modified ratios, modified peptides, and residue-level information). The NanoPOMP protocol, however, led to footprinting of both the transmembrane and extramembrane regions of hGLUT1 (Fig. 3a, b). We found that 11 of 12 transmembrane helices (TM) were footprinted. For TM2, 3, 4, and 12, more than one site became modified (Fig. $3 \mathrm{c}$ shows an example of the EIC of peptide 232-251). By comparing the product-ion $\left(\mathrm{MS}^{2}\right.$ ) spectra of the two peptides (Fig. 3d), we identified the footprinting site to be M244. (Detailed information, including mass spectra, EICs, identities of modified peptides and residues, and modification extents for all other footprinted peptides are in Supplementary Table 4. Examples of EICs, mass spectra, and $\mathrm{MS}^{2}$ spectra of labeled and unlabeled peptides are in Supplementary Figs. 18-25).

This protocol may be useful to probe the interaction of IMPs with small-molecule drugs where assessing conformational change of a protein upon interaction is a major challenge. To test whether NanoPOMP can provide a meaningful footprint of the conformational changes induced by ligand binding, we expanded our study to include interactions of hGLUT1 with $D$ maltose (Mal) and cytochalasin B (CyB). Mal binding affords an outward-open whereas $\mathrm{Cyb}$ binding gives an inward-open conformation $^{42-44}$, a typical situation with membrane transporters. The structure of hGLUT1 in its inward-open conformation is known ${ }^{42,45}$, whereas its outward-open conformation can be reliably modeled from bovine GLUT5 structure because their structures are highly similar; in their inward-facing conformation, the root mean square deviation RMSD $(\mathrm{Ca}-\mathrm{Ca})$ between their structures (PDB 4PYP and 4YB9) is only $1.4 \AA^{46}$.

To test the capability of NanoPOMP to follow the conformational changes, we used it in a typical differential footprinting experiment to probe the structural differences of the two hGLUT1 conformations. In this way, we address changes in higher order structure at the peptide/residue level by comparison of footprinting the two ligand-bound states ${ }^{14,47}$. We then compare the footprinting results with the changes in solvent accessible surface area (SASA) that are calculated from the two structures. Changes in SASA can evaluate the extent of protection/exposure (i.e., a conformational change leading to an increase in SASA causes increased modification whereas ligand binding decreases the SASA of critical binding residues and lowers their modification extents (protection)). The design acknowledges that footprinting is usually a differential experiment in which results are compared with the ligand absent or present ${ }^{47}$.

The fraction modified at the residue level (Fig. 4a) of the Mal/ $\mathrm{CyB}$ bound vs. unbound states can be classified in four groups owing to different underlying mechanisms. The first group of residues, M13 and $\mathrm{F} 444$, shows modification increases upon binding to $\mathrm{CyB}$ and decreases when binding to Mal. These sites are undergoing significant conformational change during the rocker-switch motion of the transporter between inward- and outward-facing conformations. Comparing the two structures in Fig. 4d (CyB-binding and modeled Mal-binding structure), we 

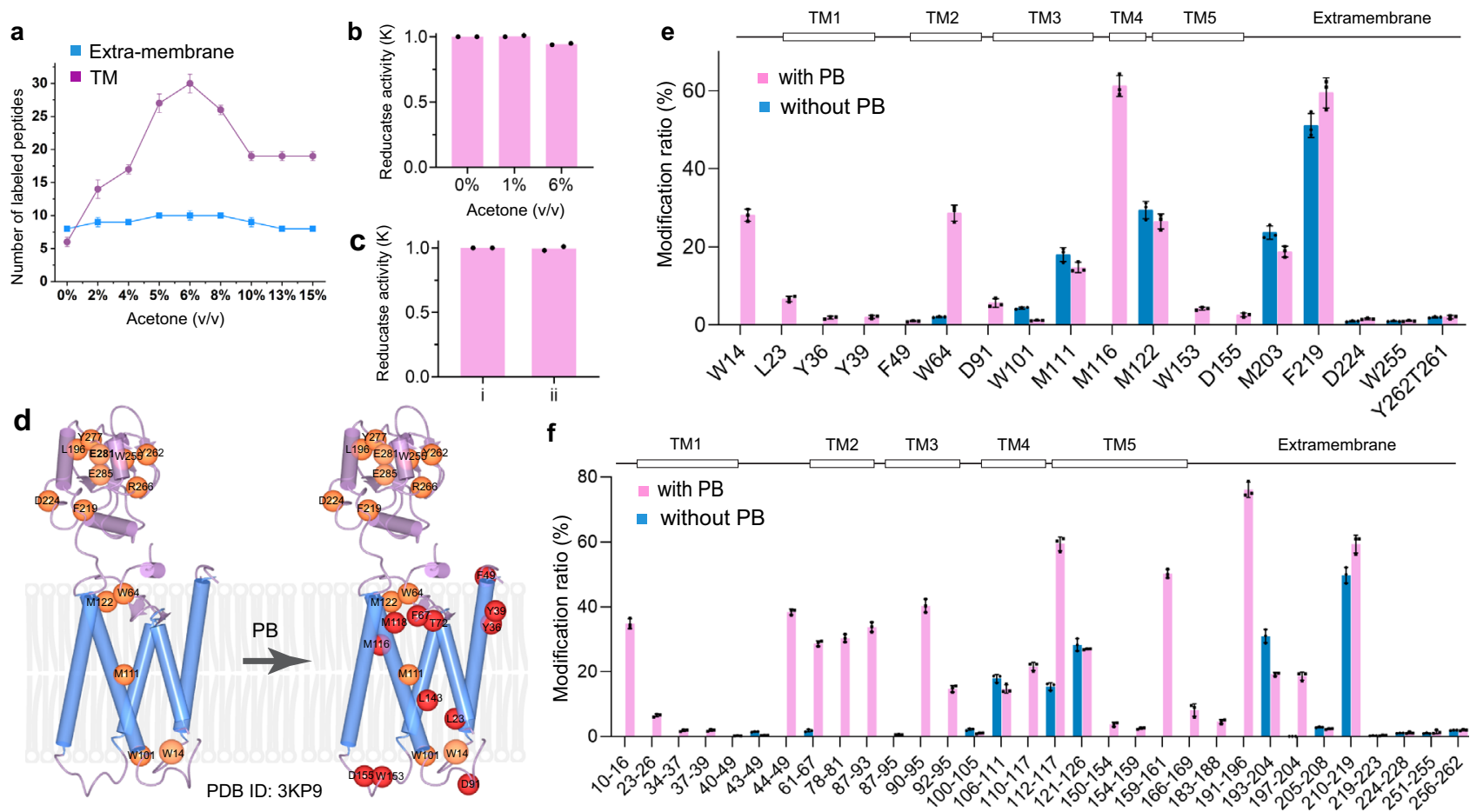

Fig. 2 NanoPOMP performance on VKOR. a The number of labeled peptides for the extra-membrane and TM regions of VKOR (PDB ID: $3 K P 940$ ) as a function of the amount of acetone (blue-extra-membrane; purple-TM) ( $n=3$ independent experiments per group, data are presented as mean values \pm SD). $\mathbf{b}$ Enzyme activity of VKOR in liposome in presence of different amount of acetone ( $n=2$ independent experiments per group, data are presented as mean values and dots represent the two corresponding individual repeats). c Enzyme activity of $\mathrm{VKOR}$ in liposome (i) without $\mathrm{TiO}_{2} \mathrm{NPs}_{1}$ and (ii) with $\mathrm{TiO}_{2}$ NPs. $n=2$ independent experiments per group, data are presented as mean values and dots represent the two corresponding individual repeats. d Cartoon diagram showing sites labeled by NanoPOMP. Red circles represent modified sites in the TM with PB reaction, and orange

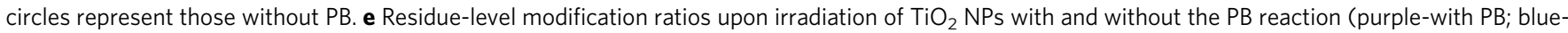
without PB). $n=3$ independent experiments per group, data are presented as mean values \pm SD and dots represent the corresponding individual repeats. f Modification ratios at peptide level (purple-with PB; blue-without PB). $n=3$ independent experiments per group, data are presented as mean values \pm SD and dots represent the corresponding individual repeats. Source data are provided as a Source Data file.

conclude the helices bearing M13 and F444 move outward for $\mathrm{CyB}$ binding, opening that region for modification, and these conclusions are consistent with the modification level changes determined by NanoPOMP. Moreover, the calculated SASA difference of CyB-binding vs. Mal-binding shows an increase for an inward- and a decrease for the outward-facing conformations (Supplementary Fig. 26), confirming again that MS-based footprinting reflects ligand-induced conformational changes, in this case, of a human IMP.

Having demonstrated that NanoPOMP is capable of revealing the conformational change induced by ligand binding, we utilized NanoPOMP to identify the transmembrane residues that interact with the two ligands, $\mathrm{CyB}$ and $\mathrm{Mal}$. The second group of residues (Fig. 4a, M77 and F379) show decreased modification upon binding with both $\mathrm{CyB}$ and $\mathrm{Mal}$, indicating that both residues are involved in binding with $\mathrm{CyB}$ and Mal. In addition to the footprinting results, two other observations show that M77 and F379 are likely part of the binding pocket. (i) The distances between these ligands and the amino acid residues in the model of the outward-open (Fig. 4b) and known inward-open (Fig. 4c) structure are in the range of non-covalent interactions that are directly involved in the binding of these ligands. (ii) According to the literature, F379 from hGLUT1 has interactions with $\mathrm{Cyb}^{42}$. These results advance the understanding of the hGLUT1 binding sites by a MS-based method and should enable the design and optimization of more specific inhibitors for human IMP, especially when combined with outcomes of other methods (CryoEM and modeling).
Furthermore, NanoPOMP reveals structural changes upon ligand binding. In Fig. 4a, the third group of F72, I339, and F437 show modification level increases compared to the unbound state for both $\mathrm{CyB}$ and Mal binding, suggesting these residues are rigid or buried in the unbound state. Upon ligand binding, they may become more flexible or orient outward and become accessible to footprinting (Fig. 4e). Similar to our footprinting that clearly detects the conformational change between the two ligand-binding states, here such change of footprints, far from the ligand-binding sites, may originate from conformational exposure induced upon ligand binding to the apo protein. Notably, the crystal structure of hGLUT1 in its unbound state cannot be obtained without stabilizing mutations owing to the intrinsic flexibility required for the protein to execute its transporter function ${ }^{48}$. Thus, utilization of NanoPOMP provides the first insight to understand the unbound state and free motion of hGLUT1.

NanoPOMP with isopropanol. As a control experiment to verify the importance of the $\mathrm{PB}$ reaction, we compared the acetone results with those of a similar organic solvent, isopropanol (IPA), that cannot participate in a $\mathrm{PB}$ reaction. We incorporated several amounts of IPA $(2 \%, 4 \%$, and $6 \%)$ with hGlut1-liposome and compared the results with the acetone/hGlut1 system. IPA does increase the labeling coverage for the transmembrane domain of hGLUT1 but at lower efficiency than produced with acetone. Although IPA at $6 \%$ gives the highest yield (Supplementary Table 5) and footprints TM2, 6, 8, 10, and 12, almost all TM 


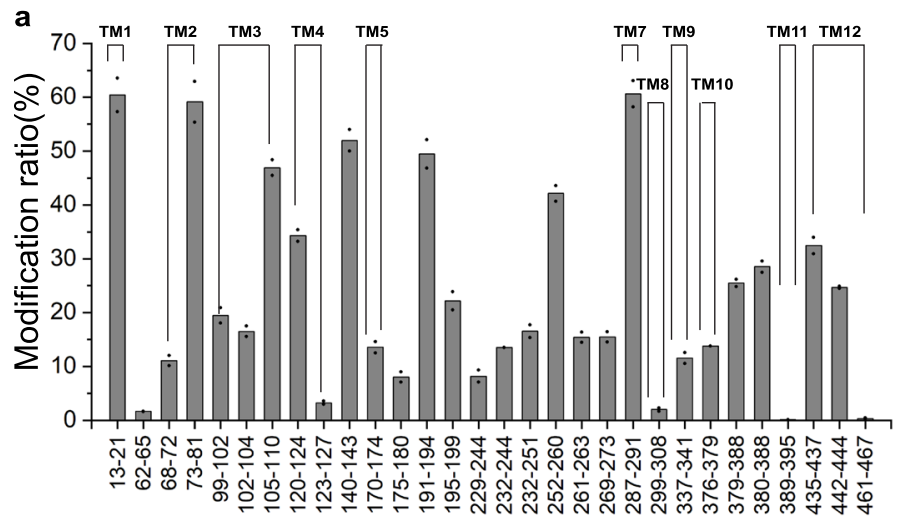

d

b

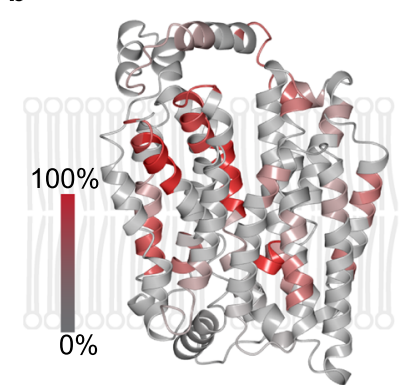

c

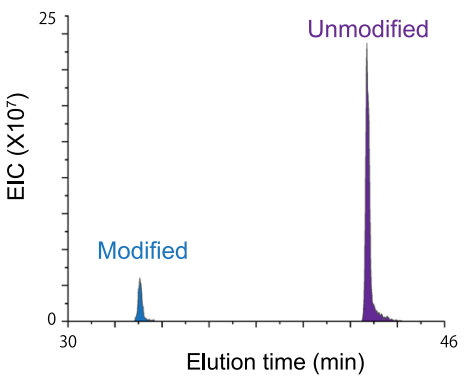

Fig. 3 NanoPOMP of hGLUT1 in liposome. a Modification ratios at the peptide level. $n=2$ independent experiments were repeated, two technical replicates (injections) were conducted for each individual sample. Data are presented as mean values of two biological repeats and dots represent the two corresponding biologically repeats. $\mathbf{b}$ Heat map (shaded in red) of the modification extents at the peptide level. c Extracted ion chromatogram of modified and unmodified representative peptide 232-251. d CID product-ion (MS2) spectra of modified and unmodified peptide 232-251. Source data are provided as a Source Data file.

regions are footprinted with $6 \%$ acetone following the $\mathrm{PB}$ reaction (Fig. 3a). That addition of IPA increases footprinting may be because, as an organic solvent, it increases the liposome permeability. Based on these results, we reiterate that NanoPOMP promotes footprinting primiarly because of the $\mathrm{PB}$ reaction.

\section{Discussion}

Overall, NanoPOMP is suitable for membrane protein footprinting. The approach makes use of the same platform as FPOP without the requirement of additional instrumentation. The likely reactive species in $\mathrm{TiO}_{2}$ photocatalysis are the holes on the $\mathrm{TiO}_{2}$ surface, hydroxyl radicals, superoxide ions, and singlet oxygen, in addition to trace amounts of $\mathrm{H}_{2} \mathrm{O}_{2}$ and $\mathrm{O}_{2}$. The rate constant for reaction of the hydroxyl radical, however, is significantly larger than those of superoxide ion or singlet oxygen ${ }^{24}$. Moreover, the oxidation of a protein is more likely to occur by hydroxyl radicals than by surface holes of $\mathrm{TiO}_{2}$, given that the protein is not attached directly to the surface of $\mathrm{TiO}_{2}$. It was also suggested that molecules need to be adsorbed onto the $\mathrm{TiO}_{2}$ surface to react with the short-lived singlet oxygen (lifetime $2-3 \mu \mathrm{s}$ ), so it is less likely that singlet oxygen oxidizes the protein ${ }^{49,50}$. Hence, in NanoPOMP, hydroxyl radicals likely play the major role in initiating the footprinting. Similar with FPOP, NanoPOMP provides a snapshot of the native protein. Although the protein may incur some structural changes due to the modification, the native state is captured by oxidation of the protein surface, and any modification-induced structural changes that occur later are unimportant. Further, NanoPOMP produces radicals in a localized manner at the surface of the liposomes. In addition, the NanoPOMP process does not require a conventional scavenger (e.g., histidine for soluble proteins) because such a scavenger likely would not enter the lipid bilayer given its larger size and its hydrophilicity. Besides, the generated hydroxyl radicals upon laser irradiation are admitted to the lipid bilayer and react with the membrane protein, whereas the excess radicals may be scavenged by reacting with double bonds of the lipids, for which they generate lipid peroxide $(\mathrm{LOOH})$ as final product. In other words, the scavenging effect of lipids on the inside radicals may be larger than conventional scavengers.

To use NanoPOMP to probe the higher order structure of IMPs, we recommend differential experiments as are used in FPOP, HDX, and other footprinting. Such measurements compare two states of a protein (e.g., bound vs. unbound, wild-type vs. mutant). Differential experiments allow any adventitious effects that affect footprinting to cancel, leaving any differences in footprinting to represent changes in solvent accessibilities of the two states.

In summary, this approach enables footprinting of IMPs in the transmembrane regions. Even more importantly, the approach can help to identify those amino acid residues of a human IMP that interact with inhibitors, suggesting that binding of small molecules to IMPs in drug development can be determined when combined with other methods. The speed of this method may be useful when a small library of compounds must be evaluated for their interactions with a target protein. This form of footprinting also reports on conformational change of IMPs upon binding. Thus, the door is opening to undertake essential but difficult experimental tasks of viewing motions of critical amino acid residues, especially when conformational flexiblity precludes structure determination by crystallography and cryo-EM. The NanoPOMP approach may be the foundation of a streamlined strategy for structural proteomics of IMPs, with applications in small-molecule drug design, binding, and screening.

\section{Methods}

Preparation of VKOR/liposome system. The VKOR membrane protein was expressed and purified as a bacterial homolog 40 . The VKOR-liposome system was 
a
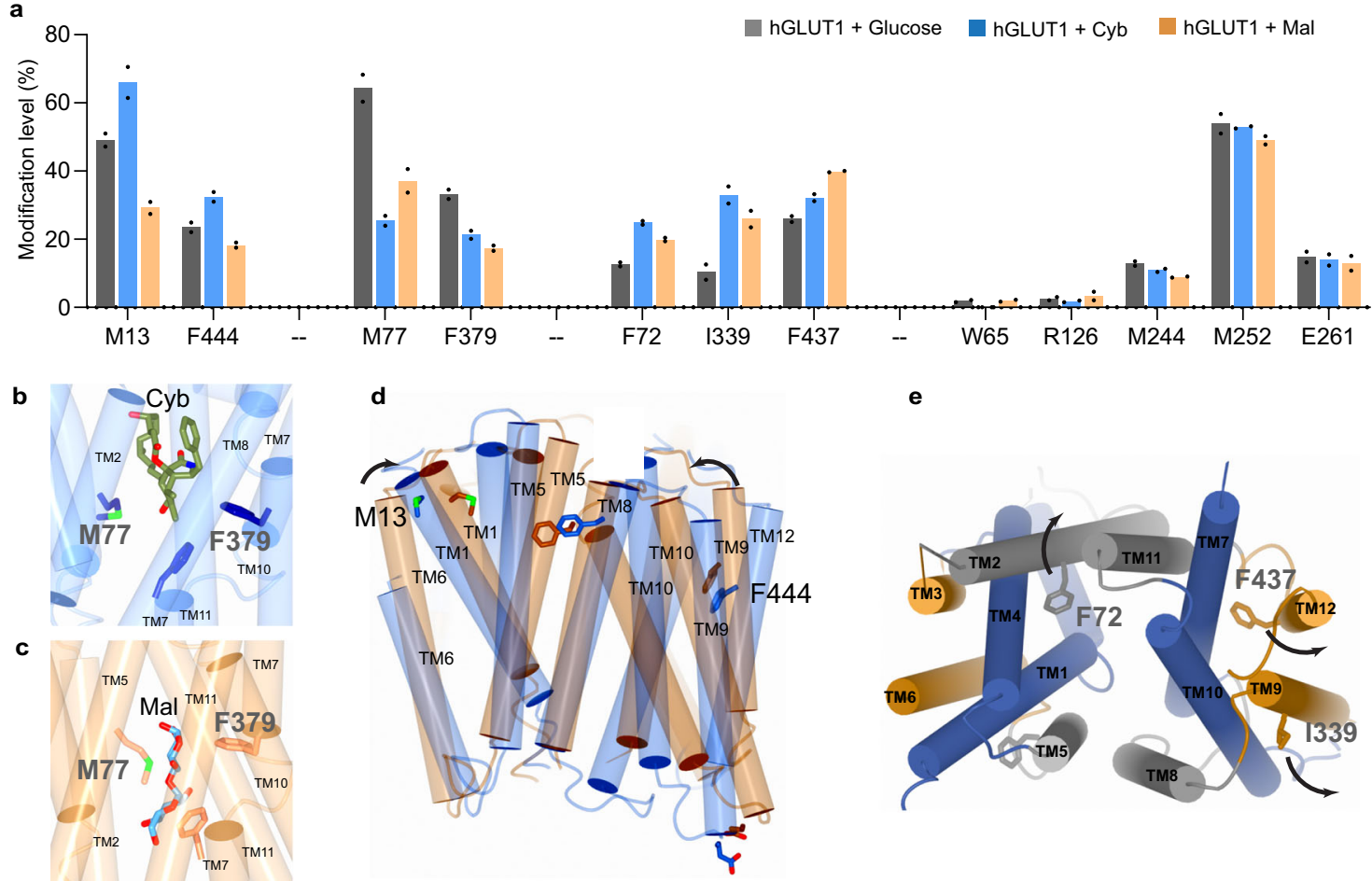

e

Fig. 4 NanoPOMP helps to reveal conformational change and ligands binding. a Modification extents at the residue level for three binding states of hGLUT1 (grey-hGlut1 + Glucose; blue-hGlut1 + Cyb; orange-hGlut1 + Mal). $n=2$ independent experiments were repeated, two technical replicates (injections) were conducted for each individual sample. Data are presented as mean values of two biological repeats and dots represent the two corresponding biologically repeats. Source data are provided as a Source Data file. b, c Residues interacting with CyB and Mal as identified by NanoPOMP. d Residues reporting conformational change (indicated by arrows) from the Mal-binding state to CyB-binding state. e Residues reporting conformational changes from unbound state to CyB-/Mal-binding state.

comprised of VKOR: lipids $=1: 25$ (weight:weight). POPE $(300 \mu \mathrm{L}$ of 1-palmitoyl2-oleoyl-sn-glycero-3-phosphoethanolamine) in dichloromethane and $100 \mu \mathrm{L}$ POPG (1-palmitoyl-2-oleoyl-sn-glycero-3-phospho-1'-rac-glycerol sodium salt) in dichloromethane were mixed in a clean glass tube $(5 \mathrm{~mL})$, and the solvent slowly evaporated with nitrogen gas flow. The dried lipid membrane in the glass tube was stored in a vacuum chamber for $60 \mathrm{~min}$ to remove completely the dichloromethane. PBS buffer $(900 \mu \mathrm{L} 1 \times, \mathrm{pH} 7.54)$ and $100 \mu \mathrm{L}$ sodium cholate hydrate solution $\left(60 \mathrm{mg} / \mathrm{mL}\right.$ in $\left.\mathrm{H}_{2} \mathrm{O}\right)$ were added to the glass tube and sonicated for $30 \mathrm{~min}$ until the suspension was clear and transparent. VKOR protein solution $(6.66 \mu \mathrm{L}$, $60 \mathrm{mg} / \mathrm{mL}$ ) was added to the lipid solution. The protein-lipid mixture was then added to pre-balanced resin columns (Sephadex ${ }^{\mathrm{TM}} \mathrm{G}-50$ Fine), the columns were immediately centrifuged under $1500 \mathrm{~g}$, and the liposome solution after centrifugation was collected. The liposome solution was then centrifuged under $110,000 \mathrm{~g}$ to obtain a liposome pellet that was resuspended with $50 \mu \mathrm{L}$ Tris buffer $(1 \times, \mathrm{pH} 7.54)$ to obtain $100 \mu \mathrm{M}$ of VKOR theoretically.

Preparation of hGLUT1/liposome system. The hGLUT1 protein was overexpressed in human $293 \mathrm{~S}$ cells by using a Bacmam system ${ }^{51}$, and purified by cobalt affinity and size-exclusion chromatography. HEK293 GnTI-suspension cells (Nacetylglucosaminyltransferase I-negative) were purchased from ATCC (American Type Culture Collection, Manassas, USA). The hGLUT1 was incorporated into liposomes by using the following protocol. POPE ( $300 \mu \mathrm{L}$ in dichloromethane) and $100 \mu \mathrm{L}$ POPG in dichloromethane were mixed in a clean glass tube $(5 \mathrm{~mL})$, and the solvent slowly removed under a nitrogen gas flow. The dried lipid membrane in the tube was admitted to a vacuum chamber for $60 \mathrm{~min}$ to remove completely the dichloromethane. PBS buffer $(900 \mu \mathrm{L}, 1 \times, \mathrm{pH}$ 7.54) and $100 \mu \mathrm{L}$ sodium cholate hydrate $\left(60 \mathrm{mg} / \mathrm{mL}\right.$ in $\left.\mathrm{H}_{2} \mathrm{O}\right)$ were added to the glass tube and sonicated for $30 \mathrm{~min}$ until the suspension was clear and transparent. hGLUT1 protein solution $(71.4 \mu \mathrm{L}$, $5.6 \mathrm{mg} / \mathrm{mL}$ ) was added to the lipid solution. The protein-lipid mixture was added to the pre-balanced resin columns (SephadexTM G-50 Fine), the columns immediately centrifuged at $1500 \mathrm{~g}$, and the liposome solution collected. That solution was centrifuged at $110,000 \mathrm{~g}$ to obtain a liposome pellet that was resuspended with $50 \mu \mathrm{L}$ Tris buffer $(1 \times \mathrm{pH} 7.54)$ to obtain $100 \mu \mathrm{M}$ hGLUT1 theoretically.

Cryo-EM imaging of liposome and liposome- $\mathrm{TiO}_{\mathbf{2}}$ NPs. (1) Liposome preparation: POPE $(300 \mu \mathrm{L})$ in dichloromethane and $100 \mu \mathrm{L}$ POPG in dichloromethane were mixed in a clean glass tube $(5 \mathrm{~mL})$, and the solvent slowly evaporated with dry nitrogen gas flow. The dried lipid membrane in the glass tube was stored in a vacuum chamber for
60 min to remove completely the dichloromethane. PBS buffer ( $900 \mu \mathrm{L} 1 \times, \mathrm{pH} 7.54)$ and $100 \mu \mathrm{L}$ sodium cholate hydrate solution $\left(60 \mathrm{mg} / \mathrm{mL}\right.$ in $\left.\mathrm{H}_{2} \mathrm{O}\right)$ were added to the glass tube and sonicated for $30 \mathrm{~min}$ until the suspension was clear and transparent. The mixture was then added to pre-balanced resin columns (SephadexTM G-50 Fine), the columns were immediately centrifuged under $1500 \mathrm{~g}$, and the liposome solution after centrifugation was collected. (2) Freeze-thaw sample: The sample was frozen at liquid nitrogen and thawed at room temperature three times. The samples were stored at room temperature until they were imaged by Cryo-EM. (3) On the day of imaging, the sample was extruded 21 times. One of the metal rings onto the main body of the extruder was screwed in place, and the open side placed up on a tabletop. One white piece and mesh were placed in the body of the extruder, mesh screen side up, and a few drops of $1 \times$ dialysis buffer were placed onto the mesh. Forceps were used to place a $400 \mathrm{~nm}$ Whatman filter onto the mesh. The other white piece was placed in the metal body of the extruder, mesh side down. Another metal ring was placed on the main body of the extruder. Some $1 \times$ dialysis buffer was drawn into one of the syringes, removing any bubbles. Both syringes were attached to the body of the extruder, and the $1 \times$ dialysis buffer was passed from side to side a few times to remove bubbles, and the process was repeated until no bubbles remain. A volume of $400 \mu \mathrm{L}$ of $1 \times$ dialysis buffer was drawn up with the syringe not used in the previous step, air bubbles removed, and the solution passed back and forth between the two syringes 21 times. A volume of $350-400 \mu \mathrm{L}$ of liposome sample was drawn into one of the syringes by using a disposable $18 \mathrm{~g}$ needle. The syringes were attached to the extruder, and the sample was passed 21 times. The extruded sample was passed into a clean tube. After $1 \mathrm{~h}$ incubation of NPs with liposome at RT, the sample was frozen immediately and imaged instantly. The samples were applied to glow-discharged Lacey carbon support films (electron microscopy sciences, Hatfield PA) in $3 \mu \mathrm{L}$ drops, blotted, and imaged at $120 \mathrm{kV}$ in the microscope.

Conditions for NanoPOMP of VKOR in liposome. $\mathrm{TiO}_{2}$ NPs (mixed phase of pure ST-01 Anatase titanium dioxide NPs and P25 TiO $\mathrm{NPs}(1: 1, \mathrm{wt}$ : wt), $5 \mathrm{~nm}$ in diameter) were suspended in water (equivalent to $200 \mathrm{mM}$ ) as a stock solution just prior to use. The sample suspension $(50 \mu \mathrm{L})$ was gently stirred in the dark for 30-60 min to allow the establishment of the adsorption-desorption equilibrium between the liposome and $\mathrm{TiO}_{2} \mathrm{NPs}$. The final concentration of $\mathrm{TiO}_{2} \mathrm{NPs}$ was $20 \mathrm{mM}$. The FPOP system we used contains a laser setup and flow system (Supplementary Fig. 1) ${ }^{16,47}$. Specifically for NanoPOMP, the operating workflow used a $248 \mathrm{~nm} \mathrm{KrF}$ excimer laser (GAM Laser Inc., Orlando, FL) to photo-excite the $\mathrm{TiO}_{2}$ NPs. A syringe pump was connected to a silica capillary terminating in a collection tube. A $75 \mu \mathrm{m}$ id capillary was used to increase the utilization rate of the laser photons. After 
setting up the laser, the laser spot width was measured. By considering the I.D. of the capillary, the illuminated volume of a single laser shot was calculated as

$$
\text { Illuminated volume }=\left(\frac{\text { I.D. } \times 0.001}{2}\right)^{2} * \Pi * \text { spot width }
$$

With the exclusion volume, the total volume with a single laser shot was given as

$$
\text { Total volume }=\frac{\text { Iluminated volume }}{1-\text { exclusion fraction }}
$$

Together with the laser frequency $(7.4 \mathrm{~Hz})$, the flow rate was calculated as

$$
\text { Flow rate }=\text { laser frequency } * 60 * \text { total volume }
$$

The exclusion volume was $15 \%$; the laser energy was $23 \mathrm{~mJ}$ per pulse. The polyimide coating of the capillary was removed along a small section of the tube exterior to give a transparent window for the laser beam. The laser beam was restricted by an iris and focused by three convex lenses to pass through the transparent window. In this experiment, a $50 \mu \mathrm{L}$ sample in each tube containing different concentrations of $\mathrm{PB}$ reactant (acetone) were tested. The laser pulse frequency was controlled by an external pulse generator (B\&K Precision, Yorba Linda, CA). After footprinting, the samples collected in vials were centrifuged to precipitate the NPs. The supernatant and NP suspension were collected separately and submitted to FASP.

Removal of lipids and proteolysis before MS detection. Following FPOP, the labeled VKOR and hGLUT1 samples were submitted to a FASP protocol before nHPLC-MS analysis. The FASP protocol was modified slightly on the basis of previous literature ${ }^{41}$. Specifically, ultrafiltration units (Microcon $30 \mathrm{kDa}$ MW cut off) containing $100 \mu \mathrm{L}$ membrane proteins (after labeling, $5 \mu \mathrm{M}$ concentration in theory) were added to $150 \mu \mathrm{L}$ of denaturing solution containing $8 \mathrm{M}$ urea (in $0.1 \mathrm{M}$ ammonium bicarbonate, $\mathrm{pH} 8.0$ ) in the ultrafiltration units and centrifuged at $10000 \mathrm{~g}$ for $\sim 15 \mathrm{~min}$ until nearly all the sample passed through the filter. Then $200 \mu \mathrm{L}$ denaturing solution was added to the ultrafiltration unit, and the wash step was repeated two more times. This step removed the lipids and salts from the membrane protein system and denatured the proteins. The solution in the collection tubes was discarded, and $100 \mu \mathrm{L} 50 \mathrm{mM}$ TCEP in $0.1 \mathrm{M}$ ammonium bicarbonate was added to the filter and incubated at $37^{\circ} \mathrm{C}$ for $30 \mathrm{~min}$. Then $100 \mu \mathrm{L}$ $100 \mathrm{mM}$ iodoacetamide (IAA) was added to the filter, and the solution incubated in the dark for $30 \mathrm{~min}$, centrifuged at $10000 \mathrm{~g}$ until all the solution passed through the filter ( $1 \mathrm{~h}$ or more required). To that solution was added $150 \mu \mathrm{L}$ digestion buffer $\left(0.1 \mathrm{M} \mathrm{NH}_{4} \mathrm{HCO}_{3}\right)$, and the solution was centrifuged at $10000 \mathrm{~g}$, and the process repeated two more times. Then the digestion buffer $\left(60 \mu \mathrm{L}\right.$ of $\left.0.1 \mathrm{M} \mathrm{NH}_{4} \mathrm{HCO}_{3}\right)$ and chymotrypsin (protein to enzyme ratio 20:1) were added to the filter and incubated overnight at $37^{\circ} \mathrm{C}$ in a water bath. After digestion, the ultrafiltration units were placed in new collection tubes and centrifuged at $10,000 \mathrm{~g}$ to collect the digested peptide solution. The fresh digestion solution $\left(50 \mu \mathrm{L}\right.$ of $\left.0.1 \mathrm{M} \mathrm{NH}_{4} \mathrm{HCO}_{3}\right)$ was added and centrifuged to the collection tube; this step was repeated two times. Formic acid $(1 \mu \mathrm{L})$ was added to the collected peptide solution, which was used for subsequent nHPLC-MS analysis.

\section{NanoPOMP of hGLUT1 in liposome with different inhibitors (Mal \& CyB). The concentration of hGLUT1-liposome was determined by using a Nanodrop (Thermo Scientific Inc., Massachusetts, USA) to be $30 \mu \mathrm{M}$. hGLUT1-liposome $(5 \mu \mathrm{L})$ was diluted to a final total volume of $50 \mu \mathrm{L}$ to give a concentration of hGLUT1-liposome that was used for PB-FPOP of $3 \mu \mathrm{M}$. Five groups of experi- ments were conducted, as listed in Supplementary Table 2. The $\mathrm{TiO}_{2} \mathrm{NPs}$ were prepared as $200 \mathrm{mM}$ stock solution. The final concentrations of Mal and CyB were 200 and $100 \mu \mathrm{M}$, respectively. All the substrates were incubated with the hGLUT1- liposome for $30 \mathrm{~min}$ at room temperature.}

nHPLC/MS/MS analysis. The digested protein sample $(15 \mu \mathrm{L})$ was diluted into $35 \mu \mathrm{L}$ water with $0.1 \%$ formic acid and centrifuged at $5000 \mathrm{~g}$ for $1 \mathrm{~min}$. The sample solution was loaded onto a custom-packed C18 reversed-phase column (Waters Symmetry, $5 \mu \mathrm{m}, 100 \AA, 75 \mu \mathrm{m} * 20 \mathrm{~cm}$ ) at $4 \mu \mathrm{L} / \mathrm{min}$ for seperation. Gradients for HPLC were comprised of (A) water with $0.1 \%$ formic acid by volume and (B) $80 \%$ acetonitrile with $0.1 \%$ formic acid by volume for an HPLC gradient of $0-10 \min 2 \% \mathrm{~B}, 10-90 \mathrm{~min} 2 \% \mathrm{~B}$ to $60 \% \mathrm{~B}, 90-100 \mathrm{~min} 2 \% \mathrm{~B}$ to $98 \% \mathrm{~B}, 100-105 \min 90 \% \mathrm{~B}, 105-115 \min 90 \%$ B to $2 \%$ $B$ and equilibrate at $2 \% B$ for $5 \mathrm{~min}$. A Thermo $Q$ Exactive Plus orbitrap mass spectrometer (Thermo Scientific, Waltham, MA, USA) coupled with a Nanospray Flex source for downstream detection with $3.0 \mathrm{kV}$ spray voltage at $250^{\circ} \mathrm{C}$ was used. Spectra were acquired in the positive-ion mode over a $300-2000 \mathrm{~m} / \mathrm{z}$ range at a mass resolving power of 70,000 for MS ${ }^{1}$ and 16,700 for $\mathrm{MS}^{2}$. Results were acquired in the datadependent mode, where the ten most abundant ions were selected for "higher energy" collisional dissociation (HCD). Signals $>+6$ charge state were rejected.

Data analysis. The nHPLC-MS/MS raw files were processed by the Byonic ${ }^{\mathrm{TM}}$ software (Protein Metrics, San Carlos, CA, USA) to reveal sequence coverage (20 $\mathrm{ppm}$ precursor mass tolerance, $60 \mathrm{ppm}$ fragmentation mass tolerance, and CID/ HCD fragmentation for searching). The automatically searched results were checked manually with a custom program, Thermo Xcalibur (Thermo Scientific, Waltham, MA, USA). Residue-level modifications were assigned based on product- ion spectra and were further validated by manual inspection of the $\mathrm{MS}^{2}$ fragmentation. The modification ratios were calculated based on the manually selected extracted ion chromatograms (EIC) area ratios according to the following equation:

$$
\text { Fraction modified }=\frac{\sum I_{\text {oxidation }}}{\sum I_{\text {oxidation }}+\sum I}
$$

Protein structures were displayed using PYMOL 2.3.2.

Circular dichroism spectrum of membrane protein. CD spectra were acquired on a J-815 OD spectrometer (Jasco Incorporated, Easton, Maryland, USA): $500 \mu \mathrm{L}$ VKOR protein $(2 \mu \mathrm{M})$ was added to the cell with or without acetone and the spectrum was acquired from 190 to $320 \mathrm{~nm}$.

VKOR enzymatic activity assay. For testing the influence of acetone, the reaction was initiated by mixing $40 \mu \mathrm{L}$ of $1 \mu \mathrm{M}$ VKOR proteoliposome with equal volume of PBS buffer (pH 7.54) containing $120 \mu \mathrm{M}$ vitamin $\mathrm{K}$ and $12.5 \mathrm{mM}$ DTT. The fluorescence of the reaction product (vitamin $\mathrm{K}$ hydroquinone) was measured on a SpectraMax M5 (Molecular Devices, Inc., USA). The excitation and emission wavelengths were 250 and $430 \mathrm{~nm}$, respectively. For testing the effects of $\mathrm{TiO}_{2} \mathrm{NPs}$ on the protein the reaction was initiated by mixing $40 \mu \mathrm{L}$ of $5 \mu \mathrm{M}$ VKOR proteoliposome (without and with NPs) with equal volume of PBS buffer (pH 7.54) containing $120 \mu \mathrm{M}$ vitamin $\mathrm{K}$ and $12.5 \mathrm{mM}$ DTT. The fluorescence of the reaction product (vitamin $\mathrm{K}$ hydroquinone) was measured on a SpectraMax M5 (Molecular Devices, Inc., USA). The excitation and emission wavelengths were 250 and $430 \mathrm{~nm}$, respectively.

Model building of outward-open hGLUT1. The outward-opening conformation of GLUT1 was generated from homology modeling, by using one-to-one threading in Phyre $2^{52}$ with the structure of the GLUT3 in the outward-opening conformation (PDB: $4 \mathrm{ZWC})^{53}$ as the template.

Reporting summary. Further information on research design is available in the Nature Research Reporting Summary linked to this article.

\section{Data availability}

The mass spectrometry proteomics data have been deposited in the ProteomeXchange Consortium via the PRIDE partner repository with the dataset identifier PXD027819. $\mathrm{MS}^{2}$ spectra generated are provided in the Supplementary Information. The structures of VKOR and GLUT proteins used in this study were previously published and are available in the Protein Data Bank (PDB) under the accession codes 3KP9, 4PYP, 4YB9, and 4ZWC. Source data are provided with this paper.

Received: 28 February 2021; Accepted: 5 October 2021; Published online: 14 December 2021

\section{References}

1. Arinaminpathy, Y., Khurana, E., Engelman, D. M. \& Gerstein, M. B. Computational analysis of membrane proteins: the largest class of drug targets. Drug Discov. Today 14, 1130-1135 (2009).

2. Drenth, J. Principles-of-Protein-X Ray-Crystallography. (Springer Science \& Business Media, 2007)

3. Henderson, R., Baldwin, J. M. \& Ceska, T. A. Model for the structure of bacteriorhodopsin based on high-resolution electron cryo-microscopy. J. Mol. Biol. 213, 899-929 (1990).

4. Domon, B. \& Aebersold, R. Mass spectrometry and protein analysis. Science 312, 212 (2006).

5. Barrera, N. P., Di Bartolo, N., Booth, P. J. \& Robinson, C. V. Micelles protect membrane complexes from solution to vacuum. Science 321, 243-246 (2008).

6. Hopper, J. T. et al. Detergent-free mass spectrometry of membrane protein complexes. Nat. Methods 10, 1206-1208 (2013).

7. Nielsen, A. K. et al. Substrate-induced conformational dynamics of the dopamine transporter. Nat. Commun. 10, 2714 (2019).

8. Manzi, L. et al. Carbene footprinting reveals binding interfaces of a multimeric membrane-spanning protein. Angew. Chem. 56, 14873-14877 (2017).

9. Ming, C., Bojie, Z., Weidong, C. \& Gross, M. L. Laser-initiated radical trifluoromethylation of peptides and proteins and its application to mass spectrometry based protein Footprinting. Angew. Chem. Int. Ed. 56, 14007-14010 (2017)

10. Lu, Y. et al. Fast photochemical oxidation of proteins maps the topology of intrinsic membrane proteins: light-harvesting complex 2 in a nanodisc. Anal. Chem. 88, 8827-8834 (2016).

11. Orban, T. et al. Conformational dynamics of activation for the pentameric complex of dimeric $\mathrm{G}$ protein-coupled receptor and heterotrimeric $\mathrm{G}$ protein. Structure 20, 826-840 (2012). 
12. Gupta, S. et al. Visualizing the kinetic power stroke that drives proton-coupled zinc(II) transport. Nature 512, 101-104 (2014).

13. Pan, Y., Stocks, B. B., Brown, L. \& Konermann, L. Structural characterization of an integral membrane protein in its natural lipid environment by oxidative methionine labeling and mass spectrometry. Anal. Chem. 81, 28-35 (2009).

14. Liu, X. R., Zhang, M. M. \& Gross, M. L. Mass spectrometry-based protein footprinting for higher-order structure analysis: fundamentals and applications. Chem. Rev. 120, 4355-4454 (2020).

15. Xu, G. \& Chance, M. R. Hydroxyl radical-mediated modification of proteins as probes for structural proteomics. Chem. Rev. 107, 3514-3543 (2007).

16. Hambly, D. M. \& Gross, M. L. Laser flash photolysis of hydrogen peroxide to oxidize protein solvent-accessible residues on the microsecond timescale. $J$. Am. Soc. Mass Spectrom. 16, 2057-2063 (2005).

17. Johnson, D. T., Di Stefano, L. H. \& Jones, L. M. Fast photochemical oxidation of proteins (FPOP): a powerful mass spectrometry-based structural proteomics tool. J. Biol. Chem. 294, 11969-11979 (2019).

18. Angel, T. E., Gupta, S., Jastrzebska, B., Palczewski, K. \& Chance, M. R. Structural waters define a functional channel mediating activation of the GPCR, rhodopsin. Proc. Natl Acad. Sci. USA 106, 14367-14372 (2009).

19. Gupta, S. et al. Conformational changes during the gating of a potassium channel revealed by structural mass spectrometry. Structure 18, 839-846 (2010).

20. Shanmugavadivu, B., Apell, H.-J., Meins, T., Zeth, K. \& Kleinschmidt, J. H. Correct folding of the $\beta$-barrel of the human membrane protein VDAC requires a lipid bilayer. J. Mol. Biol. 368, 66-78 (2007).

21. Choy, B. C., Cater, R. J., Mancia, F. \& Pryor, E. E. A 10-year meta-analysis of membrane protein structural biology: Detergents, membrane mimetics, and structure determination techniques. Biochimica et Biophysica Acta (BBA). Biochim. Biophys. Acta 1863, 183533 (2021).

22. Yang, Z. et al. Membrane protein stability can be compromised by detergent interactions with the extramembranous soluble domains. Protein Sci. 23, 769-789 (2014).

23. Barbara, J. J., Matthew, J. V., David, M. B., Laurie, E. L. \& Hayes, M. A. Cleavage of peptides and proteins using light-generated radicals from titanium dioxide. Anal. Chem. 79, 1327-1332 (2007).

24. Ruokolainen, M., Ollikainen, E., Sikanen, T., Kotiaho, T. \& Kostiainen, R Oxidation of tyrosine-phosphopeptides by titanium dioxide photocatalysis. $J$. Am. Chem. Soc. 138, 7452-7455 (2016).

25. Muszkat, L., Feigelson, L. \& Bir, K. A. M. L. Titanium dioxide photocatalyzed oxidation of proteins in biocontaminated waters. J. Photochem. Photobiol. B 60, 32-36 (2001)

26. Linsebigler, A. L., Lu, G., John, T. \& Yates, J. Photocatalysis on Ti02 surfaces: principles, mechanisms, and selected results. Chem. Rev. 95, 735-758 (1995).

27. Nosaka, Y. \& Nosaka, A. Y. Generation and detection of reactive oxygen species in photocatalysis. Chem. Rev. https://doi.org/10.1021/ acs.chemrev.7b00161 (2017)

28. Gao, F. et al. A novel strategy for facile serum exosome isolation based on specific interactions between phospholipid bilayers and TiO2. Chem. Sci. 10, 1579-1588 (2019).

29. $\mathrm{Ma}, \mathrm{X}$. et al. Identification and quantitation of lipid $\mathrm{C}=\mathrm{C}$ location isomers: a shotgun lipidomics approach enabled by photochemical reaction. Proc. Natl Acad. Sci. USA 113, 2573-2578 (2016).

30. Waldchen, F., Spengler, B. \& Heiles, S. Reactive matrix-assisted laser desorption/ionization mass spectrometry imaging using an intrinsically photoreactive Paterno-Buchi matrix for double-bond localization in isomeric phospholipids. J. Am. Chem. Soc. 141, 11816-11820 (2019).

31. Michel, R. \& Gradzielski, M. Experimental aspects of colloidal interactions in mixed systems of liposome and inorganic nanoparticle and their applications. Int. J. Mol. Sci. 13, 11610-11642 (2012).

32. Contini, C. et al. Size dependency of gold nanoparticles interacting with model membranes. Commun. Chem. 3, 130 (2020).

33. Okoampah, E., Mao, Y., Yang, S., Sun, S. \& Zhou, C. Gold nanoparticlesbiomembrane interactions: from fundamental to simulation. Colloids Surf. B 196, 111312 (2020).

34. Bahrami, A. H. et al. Wrapping of nanoparticles by membranes. Adv. Colloid Interface Sci. 208, 214-224 (2014).

35. Sushma Savarala, S. A., Marc, A. Ilies., \& Stephanie, L. Wunder. Stabilization of soft lipid colloids: competing effects of nanoparticle decoration and supported lipid bilayer formation. ACS Nano 5, 2619-2628 (2011).

36. Michel, R., Plostica, T., Abezgauz, L., Danino, D. \& Gradzielski, M. Control of the stability and structure of liposomes by means of nanoparticles. Soft Matter 9, 4167 (2013).

37. Zhang, L. \& Granick, S. How to stabilize phospholipid liposomes (using nanoparticles). Nano Lett. 6, 694-698 (2006)

38. Wang, $\mathrm{X}$. et al. Charge and coordination directed liposome fusion onto $\mathrm{SiO} 2$ and $\mathrm{TiO} 2$ nanoparticles. Langmuir 35, 1672-1681 (2019).

39. Hur Munawar Kabir Mohd, I. A. R., Ainee Fatimah Ahmad, Shahidan Radiman, Faizal Mohamed, Muhamad Samudi Yasir. Effect of titanium dioxide nanoparticle addition to the surface charge and structure of DPPC vesicles. Malays. J. Anal. Sci. 19 179-183 (2015).

40. $\mathrm{Li}, \mathrm{W}$. et al. Structure of a bacterial homologue of vitamin $\mathrm{K}$ epoxide reductase. Nature 463, 507-512 (2010).

41. Wisniewski, J. R., Zougman, A., Nagaraj, N. \& Mann, M. Universal sample preparation method for proteome analysis. Nat. Methods 6, 359-362 (2009).

42. Kapoor, K. et al. Mechanism of inhibition of human glucose transporter GLUT1 is conserved between cytochalasin B and phenylalanine amides. Proc. Natl Acad. Sci. USA 113, 4711-4716 (2016).

43. Carruthers, A. \& Helgerson, A. L. Inhibitions of sugar transport produced by ligands binding at opposite sides of the membrane. Evidence for simultaneous occupation of the carrier by maltose and cytochalasin B.

44. Jung Cy Fau - Rampal, A. L. \& Rampal, A. L. Cytochalasin B binding sites and glucose transport carrier in human erythrocyte ghosts.

45. Deng, D. et al. Crystal structure of the human glucose transporter GLUT1. Nature 510, 121-125 (2014)

46. Nomura, N. et al. Structure and mechanism of the mammalian fructose transporter GLUT5. doi:D-NLM: EMS64196 EDAT-2015/09/30 06:00 MHDA-2016/04/29 06:00 CRDT-2015/09/30 06:00 PHST-2015/02/19 00:00 [received] PHST-2015/07/14 00:00 [accepted] PHST-2015/09/30 06:00 [entrez] PHST-2015/09/30 06:00 [pubmed] PHST-2016/04/29 06:00 [medline] AID-10.1038/nature14909 [doi] PST-ppublish.

47. Liu, X. R., Rempel, D. L. \& Gross, M. L. Protein higher-order-structure determination by fast photochemical oxidation of proteins and mass spectrometry analysis. Nat. Protoc. 15, 3942-3970 (2020).

48. Yan, N. Structural advances for the major facilitator superfamily (MFS) transporters. Trends Biochem. Sci. 38, 151-159 (2013).

49. Daimon, T. \& Nosaka, Y. Formation and behavior of singlet molecular oxygen in $\mathrm{TiO} 2$ photocatalysis studied by detection of near-infrared phosphorescence. J. Phys. Chem. C 111, 4420-4424 (2007).

50. Daimon, T., Hirakawa, T. \& Nosaka, Y. Monitoring the formation and decay of singlet molecular oxygen in $\mathrm{TiO}_{2}$ photocatalytic systems and the reaction with organic molecules. Electrochemistry 76, 136-139 (2008).

51. Goehring, A. et al. Screening and large-scale expression of membrane proteins in mammalian cells for structural studies. Nat. Protoc. 9, 2574-2585 (2014).

52. Kelley, L. A., Mezulis, S., Yates, C. M., Wass, M. N. \& Sternberg, M. J. E. The Phyre2 web portal for protein modeling, prediction and analysis. Nat. Protoc. 10, 845-858 (2015)

53. Deng, D. et al. Molecular basis of ligand recognition and transport by glucose transporters. Nature 526, 391-396 (2015).

\section{Acknowledgements}

This study was supported by Grants from National Institutes of Health (5R01 GM13100802 to W.L. and M.L.G.) and from the American Heart Association (20CSAOI34710002). The mass spectrometry was supported by P41GM103422 and R24GM136766. Software support from Protein Metrics is also acknowledged.

\section{Author contributions}

J.S. and M.L.G. designed the study. J.S. performed most of the experiments and data analysis. X.R.L. and J.S. optimized NanoPOMP platform, mass spectrometry instrument parameters, and analyzed data. S.L. and J.S. performed enzyme activity assays and prepared proteins-liposome systems. P.H. purified hGlutl protein. W.K.L. purified vkor protein. M.L.G., W.K.L., and J.S. wrote the paper. All authors discussed the results and commented on the paper.

\section{Competing interests}

M.L.G. is an unpaid member of the advisory boards of Protein Metrics, a software development company specializing in protein footprinting, and GenNext, a start-up company seeking to commercialize FPOP for biotechnology. J.S., X.R.L., S.L., P.H., and W.K.L. declare no competing interests.

\section{Additional information}

Supplementary information The online version contains supplementary material available at https://doi.org/10.1038/s41467-021-27588-8.

Correspondence and requests for materials should be addressed to Weikai Li or Michael L. Gross.

Peer review information Nature Communications thanks Elisa Parra-Ortiz, Joshua Sharp, and the other, anonymous, reviewer(s) for their contribution to the peer review of this work. Peer reviewer reports are available.

Reprints and permission information is available at http://www.nature.com/reprints

Publisher's note Springer Nature remains neutral with regard to jurisdictional claims in published maps and institutional affiliations. 
(c) (i) Open Access This article is licensed under a Creative Commons Attribution 4.0 International License, which permits use, sharing, adaptation, distribution and reproduction in any medium or format, as long as you give appropriate credit to the original author(s) and the source, provide a link to the Creative Commons license, and indicate if changes were made. The images or other third party material in this article are included in the article's Creative Commons license, unless indicated otherwise in a credit line to the material. If material is not included in the article's Creative Commons license and your intended use is not permitted by statutory regulation or exceeds the permitted use, you will need to obtain permission directly from the copyright holder. To view a copy of this license, visit http://creativecommons.org/ licenses/by/4.0/.

(C) The Author(s) 2021 